\title{
Redes de afloramentos artificiais para 0 ensino de Geociências
}

\author{
Networks OF ARTificial OUTCROPS FOR TEACHing GeOSCIENCES
}

\author{
Matheus Kuchenbecker ${ }^{1,2,3}$, Geysianne Ferreira de Morais ${ }^{1,2}$, Viníclus César Maciel Silva ${ }^{1}$, João Pedro Ribeiro Pimenta ${ }^{1,2}$ \\ 1 - Laboratório de Estudos Tectônicos (LeSte/CeGeo), Univ. Federal dos Vales do Jequitinhonha e Mucuri (UFVJM), Diamantina (MG). \\ 2 - Programa de Pós-graduação em Geologia, Univ. Federal dos Vales do Jequitinhonha e Mucuri (UFVJM), Diamantina (MG). \\ 3 - Centro de Pesquisa Professor Manoel Teixeira da Costa (CPMTC), IgC/UfMg, Belo Horizonte (Mg). \\ E-MAIL: MATHEUSK@ICT.uFVIM.EDU.BR, GEEYSI@HOTMALl.COM, VINIIIUS_CESAR18@HOTMAIL.COM,.JPRIBEIROWAR@HOTMAL.cOM
}

\begin{abstract}
Students in Geology courses, along with learning about the dynamics of the Earth System, need to develop a set of practical skills: spatial and three-dimensional reasoning, drawing techniques and the use of specific equipment. Both approaches - theory and practice - are inseparable in the geologist's praxis; their integration is, therefore, central for Geology training. This paper describes the setting up of Networks of Artificial Outcrops (NAO) as a didactic strategy in the teaching of Geosciences. NAO are sets of rock samples, selected, and positioned in a certain area, seeking to simulate a specific geological situation. They are versatile and low-cost pedagogical tools, which allow the development of controlled pedagogical practices that optimize learning and training in different areas, such as Field Geology, Geological Drawing, Stratigraphy and Structural Geology. The example of a pilot network set up at the UFVJM Campus (Diamantina, Brazil) allows to discuss procedures for the dimensioning of an NAO, construction and installation of artificial outcrops and to outline the vast associated pedagogical possibilities.
\end{abstract}

Resumo: Estudantes de cursos de Geologia, junto com o aprendizado sobre a dinâmica do Sistema Terra, precisam desenvolver um conjunto de habilidades práticas: raciocínio espacial e tridimensional, técnicas de desenho e uso de equipamentos espećficicos. As abordagens - teoria e prática - são indissociáveis na práxis do geólogo; sua integração é, portanto, central para formação em Geologia. Este trabalho descreve a montagem de Redes de Afloramentos Artificiais (RAA) como estratégia didática no ensino de Geociências. RAA são conjuntos de amostras de rochas, selecionadas e posicionadas em determinada área, buscando simular uma situação geológica específica. Constituem instrumentos pedagógicos versáteis e de baixo custo, que permitem desenvolver práticas pedagógicas controladas, que otimizam 0 aprendizado e treinamento em diferentes áreas, como Geologia de Campo, Desenho Geológico, Estratigrafia e Geologia Estrutural. 0 exemplo de uma rede piloto montada no campus da UFVJM (Diamantina, MG) permite discutir procedimentos para dimensionamento de uma RAA, construção e instalação dos afloramentos artificiais e delinear as vastas possibilidades pedagógicas associadas.
Citation/Citação: Kuchenbecker, M., Morais, G. F. de Vinícius, Silva, C. M., \& Pimenta, J. P. R. (2021). Redes de Afloramentos Artificiais para 0 ensino de Geociências. Terræ Didatica, 17(Publ. Contínua), 1-11, e021013. doi: 10.20396/td.v17i00.8663959.

Keywords: Theory and practice, Geological mapping, Field Geology, Didactics, Teaching strategies.

Palavras-chave: Teoria e prática, Mapeamento geológico, Geologia de Campo, Didática, Estratégias de ensino.

\section{Manuscript/Manuscrito:}

Received/Recebido: 13/01/2021

Revised/Corrigido: 04/02/2021

Accepted/Aceito: 08/03/2021

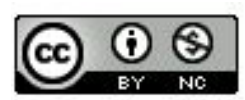

\section{Introdução}

A Geologia, como campo do saber, é uma ciência histórica, pautada na interpretação do Sistema Terra - sua formação e evolução espaço-temporal - a partir da investigação dos registros preservados na litosfera. Assim como ocorre nas demais ciências, a produção e reprodução do conhecimento geológico estão firmemente embasadas na interdependência entre teoria e prática (e.g. Carneiro et al. 1993, Fantinel, 2005, Frodeman, 2010). A dimensão prática, no entanto, apresenta diversas particularidades decorrentes da natureza do objeto de estudo da geologia, uma vez que a vasta maioria dos processos e produtos que compõem o Sistema-
-Terra ocorrem em dimensões espaciais e temporais que impedem sua reprodução em laboratório. Por este motivo, os trabalhos de campo possuem papel central na formação e atuação do geólogo, constituindo momentos de geração, análise e crítica do conhecimento (e.g. Fantinel, 2005, Scortegagna \& Negrão, 2005, Andrade \& Carneiro, 2019).

Para o desenvolvimento de atividades práticas demanda-se ao geólogo um conjunto de habilidades específicas, que incluem desde orientação espacial e raciocínio tridimensional até o uso de equipamentos e ferramentas. Tais habilidades, essenciais para o entendimento de feições e fenômenos naturais, devem ser desenvolvidas e exer- 
citadas ao longo da formação do geólogo. O locus natural deste desenvolvimento é o trabalho de campo, atividade que possui papel central no ensino (e no exercício) da geologia. Para além da dimensão de formação e treinamento, a intermediação do campo na formação do conhecimento geológico assume, também, papel epistemológico, uma vez que é por intermédio dessas práticas que se estabelecem as relações diretas entre o geocientista e seus objetos mais imediatos de investigação (Fantinel, 2005).

Tendo em vista o papel central das atividades práticas na formação e práxis geológicas, apresentamos, neste trabalho, a montagem de redes de afloramentos artificiais como uma nova metodologia para a realização de atividades didáticas formativas em cursos de geologia. A ferramenta aqui apresentada não pretende, em absoluto, substituir as atividades de campo. Ao contrário, busca-se criar um ambiente controlado no qual os discentes possam ter contato com questões e tarefas que, nos passos subsequentes de sua formação, vivenciarão na natureza.

\section{Redes de afloramentos artificiais}

Define-se aqui como "redes de afloramentos artificiais" (RAA) um conjunto de amostras de rochas, selecionadas e posicionadas em uma determinada área com o objetivo de simular uma situação geológica específica. As amostras de uma RAA devem apresentar características didáticas, como estruturas e/ou texturas, que permitam seu fácil reconhecimento e descrição. O posicionamento da amostra no espaço deve levar em consideração a orientação espacial das estruturas presentes, de acordo com a situação geológica pretendida.

A dimensão de uma RAA (i.e. a quantidade de amostras utilizadas) dependerá da complexidade da situação geológica que se pretende simular. Por exemplo, pode-se posicionar algumas poucas amostras de rochas (meta) sedimentares ao longo de um perfil, de modo que seus planos de acamamento, quando medidos, indiquem ao observador uma sequência dobrada. Por outro lado, pode-se instalar amostras de tipos variados de rocha ao longo de uma grande área para que, quando descritas em seu conjunto, sejam representativas de um determinado mapa geológico e, por conseguinte, simulem uma história geológica particular. Tendo em vista que a descrição dos afloramentos artificiais pode incluir medidas de bússola, as amostras utilizadas na sua construção devem possuir um tamanho adequado para tal atividade.

\section{A Rede de Afloramentos Artificiais da UFVJM}

A Rede de Afloramentos Artificiais da UFVJM (RAA-UFVJM) foi projetada e instalada na área do Campus JK (Diamantina, MG), para apoiar atividades didáticas do curso de Engenharia Geológica. A construção da rede foi uma iniciativa do Laboratório de Estudos Tectônicos (LESTE), no âmbito de dois editais institucionais de Projetos de Apoio ao Ensino de Graduação da UFVJM (PROAE-UFVJM).

O Campus JK da UFVJM está situado $5 \mathrm{~km}$ a norte do centro de Diamantina, às margens da BR-367, ocupando uma área de formato triangular com aproximadamente $2 \mathrm{~km}^{2}$. A área possui relevo e ocupação bastante distintos: sua porção sudoeste corresponde a um platô elevado e relativamente plano e coberto por solo que se encontra urbanizado, abrigando a maior parte das instalações da UFVJM e uma malha de ruas calçadas ou asfaltadas. As porções leste e norte, por sua vez, apresentam relevo mais acidentado e com encostas rochosas, marcado pelo vale do Córrego Soberbo, e apresentam apenas algumas poucas edificações rurais da universidade, ligadas por estradas não pavimentadas (Fig. 1A e B). As cotas variam de 1.390 a $1.270 \mathrm{~m}$.

O primeiro passo para a implementação da RAA-UFVJM foi a análise da topografia e das vias de acesso da área do Campus JK, para a determinação das possibilidades logísticas (i.e., condições de acesso, visibilidade etc.) e potencialidades cartográficas. Em seguida, idealizou-se um mapa geológico fictício para a área do campus (Fig. 1C), contendo preferencialmente unidades com litotipos presentes na região, para facilitar a obtenção de amostras. Neste mapa, garantiu-se a presença de rochas ígneas, sedimentares e metamórficas, bem como de relações de contato diversas. Optou-se por um mapa com moderada complexidade estrutural, para que as atividades didáticas utilizando a rede pudessem atender várias disciplinas, das mais básicas às mais avançadas. O mapa foi elaborado tendo-se em vista a lógica geológica e os princípios geométricos do desenho aplicado à Geologia, considerando-se a topografia existente

Em linhas gerais, o mapa proposto conta com um embasamento gnáissico, sobre o qual ocorre uma sequência metassedimentar dobrada, com dobras de eixo NE e vergência para norte. A sequência apresenta três unidades, da base para o topo: filito, quartzito e metaconglomerado. Um dique de gabro de direção NNE corta o embasamento e 

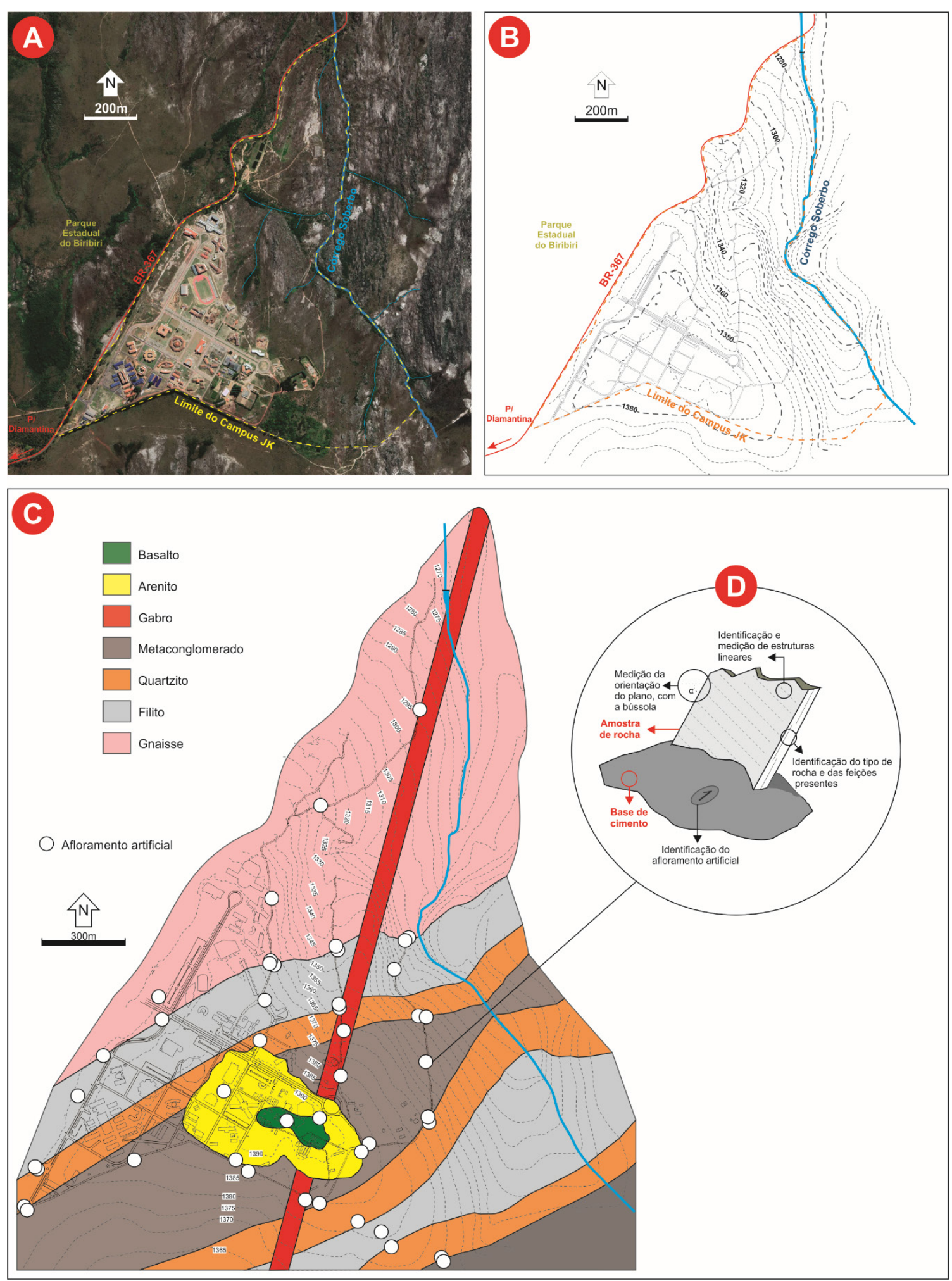

Figura 1. (A) Imagem de satélite do Campus JK. Notar a área urbanizada do Campus JK. Fonte: Google Earth. (B) Mapa topográfico do Campus JK, com curvas de nível a cada $5 \mathrm{~m}$. Notar o platô a sudoeste e o vale do Córrego Soberbo, a leste. Fonte: Plano Diretor do Campus JK (UFVJM, 2011). (C) Mapa geológico fictício do Campus JK, idealizado para a confecção da RAA-UFVJM. Notar a localização dos afloramentos artificiais na área do campus. (D) Desenho esquemático de um afloramento artificial, indicando seus componentes e os principais dados passíveis de utilização nas atividades didáticas 
sequência metassedimentar, e um pacote horizontal de arenito e basalto recobre discordantemente todo o conjunto.

Depois de elaborado o mapa geológico foram determinados os melhores locais para a instalação de afloramentos artificiais, tendo-se em vista a malha viária do Campus JK e as feições presentes no mapa. A quantidade e localização dos afloramentos artificiais foram estrategicamente pensados para fornecer informação geológica suficiente para a identificação de todas as unidades e estruturas presentes. Assim, foram projetados afloramentos de todas as unidades, bem como afloramentos em todos os flancos de dobra e outros representativos de relações específicas de contato (dique/encaixantes, arenito/basalto).

Com base no modelo idealizado, foi determinada a quantidade de amostras de cada litotipo que seria necessária obter para a instalação da rede. A grande maioria das amostras utilizadas foi coletada nos arredores de Diamantina, e apenas alguns litotipos em regiões mais distantes. Foram selecionadas amostras com feições geológicas típicas (e.g. planos de acamamento, foliações, lineações etc.) para facilitar sua identificação e descrição pelos alunos. Além disso, buscou-se selecionar amostras com características interessantes, que permitissem a elaboração de atividades didáticas mais complexas. Assim, foram coletadas amostras de quartzito com marcas de onda, filitos e gnaisses com lineações de estiramento marcantes e metaconglomerados distintos, variando a proporção clasto/matriz e o tamanho e grau de arredondamento dos clastos.

Após a obtenção de todas as amostras procedeu-se à construção dos afloramentos artificiais propriamente ditos (Fig. 1D). Foram confeccionadas bases de cimento em moldes de madeira, com tamanho variando de acordo com as dimensões das amostras. As amostras foram então parcialmente imersas no cimento ainda fresco, e o conjunto secou por alguns dias antes de ser desenformado. As amostras com estruturas planares e lineares relevantes (e.g. planos de acamamento, foliações, lineações etc.) foram cuidadosamente posicionadas na base de cimento com auxílio de uma bússola geológica, para que as estruturas mantivessem um mergulho compatível com o previsto no mapa geológico fictício (Fig. 2A).

Depois de desenformadas, as bases de cimento de todos os afloramentos artificiais foram pintadas para facilitar sua identificação quando instalados (Fig. 2B). Em seguida, cada afloramento artifi- cial foi identificado com uma placa contendo um número sequencial de controle e a altitude exata do ponto destinado à sua instalação (Fig. 2C). A determinação da altitude de cada ponto foi feita a partir da consulta a um mapa topográfico de detalhe do Campus JK, disponibilizado pela administração da UFVJM (UFVJM, 2011). A indicação da altitude na placa de cada afloramento artificial foi adotada para permitir a confecção de perfis topográficos e a execução de práticas de desenho geológico.

Os afloramentos artificiais foram transportados para os locais planejados para sua instalação e cuidadosamente posicionados com o auxílio de uma bússola geológica, de modo que sua posição espacial final refletisse a atitude indicada no mapa geológico fictício (Figs. 2D e 2E). Ao todo foram instalados 45 afloramentos artificiais pelo Campus JK (bases azuis) e seis outros foram adicionados em um segundo momento (bases vermelhas), configurando um exercício didático à parte (Fig. 2F).

$\mathrm{Na}$ montagem da RAA-UFVJM algumas feições geológicas foram pensadas para permitir atividades pedagógicas específicas, tendo em vista as características dos litotipos escolhidos, sua distribuição no mapa proposto:

- Nos afloramentos artificiais da camada de quartzito foram utilizadas diversas amostras com marcas de onda assimétricas. As cristas das marcas de onda foram posicionadas de modo a apresentar uma orientação espacial coerente quando rebatidas em um plano horizontal. Da mesma forma, a assimetria das marcas de onda foi levada em consideração, que haja coerência na indicação de paleocorrente, quando todos os afloramentos estiverem instalados.

- Ainda para a camada de quartzito, foram selecionadas amostras de diferentes granulometrias, e estas foram posicionadas de modo a indicar granodecrescência ascendente.

- Para a camada de metaconglomerado, foram selecionadas amostras com clastos de graus de arredondamento diversos. Quando da instalação dos afloramentos artificiais, a distribuição espacial destes foi feita de modo a indicar uma direção de transporte sedimentar, para a qual o arredondamento dos clastos aumentava.

- Na seleção de amostras foliadas (filitos, gnaisses e alguns quartzitos) foram escolhidas algumas amostras com lineações de estiramento bem marcadas. Durante a instalação dos aflora-

\begin{tabular}{c|c|c|c|c|c}
\hline (C) Terrae Didat. & Campinas, SP & v.17 & $1-11$ & $\mathrm{e} 021013$ & 2021 \\
\hline
\end{tabular}


mentos artificiais correspondentes, cuidou-se para que as lineações fossem posicionadas de maneira coerente com o contexto do mapa geológico fictício.

- Para o dique de gabro, foram selecionadas amostras de granulação variada. Os afloramentos artificiais correspondentes foram posicionados de modo a indicar diminuição da granulação em direção às bordas do dique. Para marcar exatamente as bordas do dique e sua orientação espacial, foram montados afloramentos artificiais de contato, em que as amostras do gabro e da rocha encaixantes foram cortadas e coladas definindo um contato vertical.

- Para explicitar as relações de contato entre o arenito e o basalto, foram fabricados afloramentos artificiais de contato, em que amostras de basalto foram coladas sobre amostras de arenito, definindo um contato horizontal.

- As amostras de gnaisse foram posicionadas com o bandamento vertical e de direção oblíqua às demais estruturas do mapa, para representar a existência de um evento tectônico mais antigo.

- Na região do mapa fictício correspondente ao contato entre o embasamento gnáissico e a cobertura metassedimentar foram posicionados afloramentos artificiais de quartzo de veio, para representar a percolação de fluidos por esta zona.

Como meio de preservação da RAA-UFVJM, os discentes são instruídos, a cada atividade, a não quebrar/martelar as rochas. Para permitir a realização de atividades em laboratório, como a descrição detalhada macro e microscópica dos litotipos que compõem a rede, foi confeccionado um kit contendo amostras com feições geológicas representativas de cada unidade do mapa geológico fictício. O kit também conta com lâminas delgadas referentes a cada uma das amostras, possibilitando o desenvolvimento de atividades didáticas multiescalares.

\section{Possibilidades didáticas}

As possibilidades pedagógicas associadas a uma RAA são inúmeras, e quanto maior a RAA, mais diversos e complexos podem se tornar os exercícios propostos. Esta versatilidade permite utilizar uma mesma RAA para atender desde disciplinas introdutórias, como por exemplo Sistema Terra (ou Introdução à Geologia, Geologia Geral) e Desenho Geológico, até disciplinas mais avançadas, como Sedimentologia, Estratigrafia e Geologia Estrutural.

A título de exemplo são descritos, abaixo, exemplos de atividades propostas para a utilização da RAA-UFVJM. Observa-se que elas envolvem desde práticas básicas, como reconhecimento e classificação de rochas e minerais, até práticas um pouco mais complexas, como o reconhecimento da distribuição espacial e relações de contato entre os diferentes litotipos e a determinação da história geológica que deles decorre. Além disso, pode-se exercitar o uso de equipamentos - como bússola geológica e GPS - e técnicas de cartografia, como a plotagem de pontos em mapa e o desenho de perfis e mapas topográficos e geológicos em diferentes escalas e com variações no tamanho da área de estudo.

\section{- Atividade 1}

É apresentado aos alunos um mapa do Campus JK com alguns pontos de afloramentos artificiais plotados. De posse de uma bússola e um GPS, pede-se aos discentes que localizem os afloramentos artificiais, guiando-se pelos elementos presentes no mapa, e coletem as seguintes informações: coordenadas de cada afloramento, descrição das rochas e medidas estruturais.

\section{- Atividade 2}

São fornecidos aos alunos as coordenadas de alguns afloramentos artificiais, um mapa do Campus JK, um GPS e uma bússola. Pede-se aos discentes que encontrem os afloramentos, plotem no mapa e coletem as descrições da rocha e medidas estruturais. Nesse exercício os alunos poderão encontrar os afloramentos inserindo as coordenadas no GPS e seguindo as indicações do aparelho ou plotando os pontos no mapa e se guiando pelos elementos de toponímia.

\section{- Atividade 3}

Indica-se aos estudantes o trajeto de um perfil perpendicular às estruturas do mapa geológico fictício e pede-se que eles, com auxílio de GPS, bússola e lupa, analisem todos os afloramentos artificiais presentes, descrevendo as rochas e tomando as medidas estruturais e as coordenadas de cada um. A partir das informações coletadas, pede-se que eles confeccionem o perfil geológico (e, por consequência, topográfico), plotem as medidas estruturais em estereograma e as interpretem. 

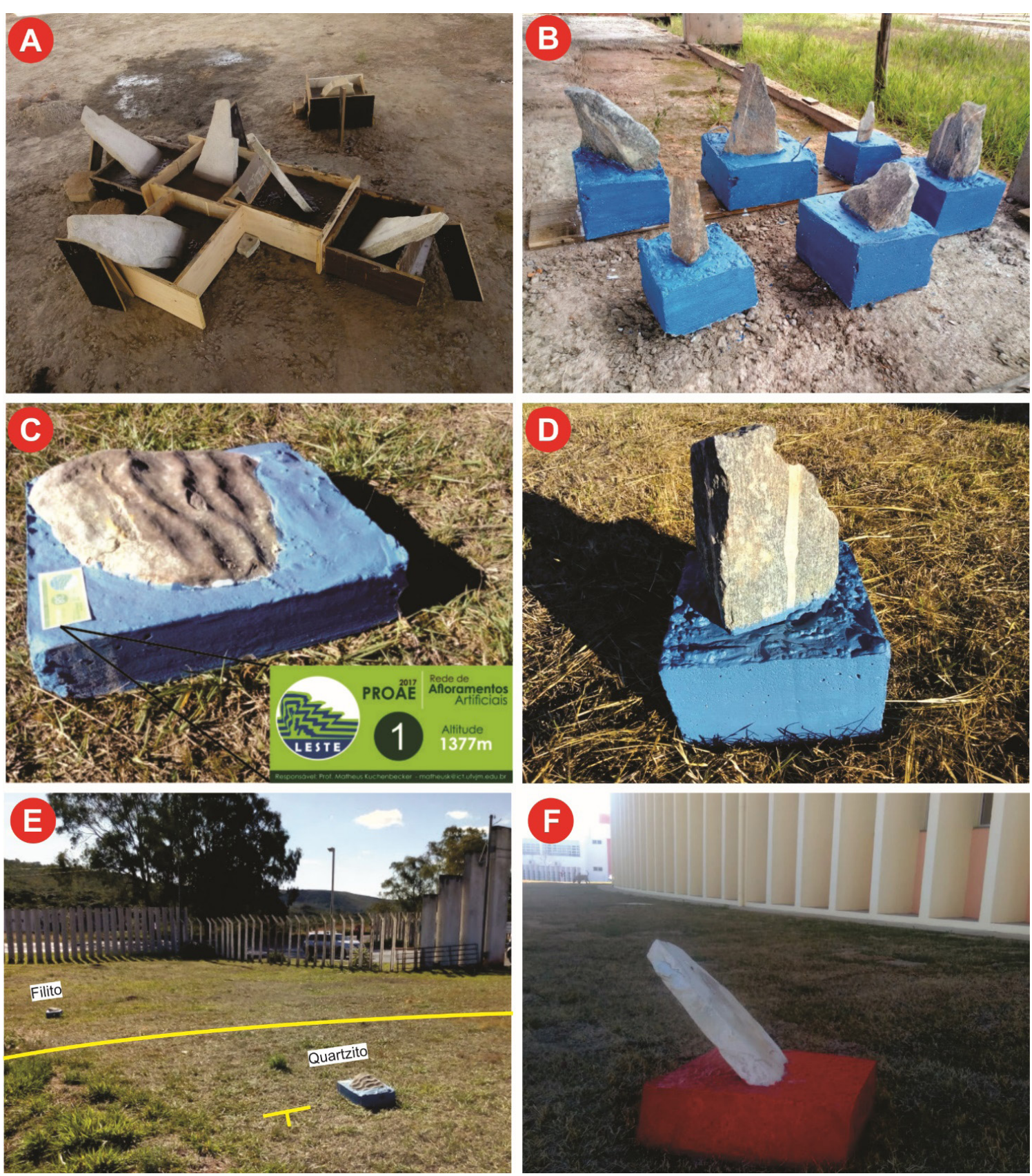

Figura 2. (A) Confecção dos afloramentos artificiais, através da fixação de amostras de rocha em bases de cimento feitas com formas de madeira. (B) Afloramentos artificiais prontos, com as bases pintadas para facilitar sua identificação. (C) Um dos afloramentos artificiais de quartzito instalados no campus. Notar a presença de marcas onduladas assimétricas. No detalhe, placa de identificação contendo o número do afloramento e sua altitude. (D) Um dos afloramentos artificiais de gnaisse instalados no campus. Notar o bandamento gnáissico vertical. (E) Afloramentos artificiais de quartzito e filito instalados próximo à entrada no Campus JK, representando um contato (indicado em amarelo). (F) Afloramento artificial de quartzito instalado ao lado de um dos prédios do Campus JK/UFVJM. A base vermelha indica que o afloramento pertence à segunda geração de afloramentos artificiais construída na UFVJM

Adicionalmente, pode-se pedir que rotacionem os planos para encontrar a orientação original das marcas onduladas.

\section{- Atividade 4}

Apresenta-se aos discentes um mapa do
Campus JK, com alguns pontos de afloramentos artificiais plotados. Solicita-se aos estudantes que encontrem os afloramentos e identifiquem o tipo da rocha. Ao retornarem com as descrições dos afloramentos, é dado aos discentes o kit contendo as amostras de mão e lâminas delgadas e pede-se a

\begin{tabular}{l|l} 
(C) Terrae Didat. & Campinas, SP
\end{tabular} \begin{tabular}{l|c|c|c|} 
v.17 & $1-11$ & $\mathrm{e} 021013$ & 2021
\end{tabular} 
descrição petrográfica detalhada dos litotipos que compõem a rede, e a confecção de um relatório sucinto sobre a geologia fictícia da área do campus.

- Atividade 5

São fornecidas aos discentes as coordenadas (ou um mapa plotado) de todos os afloramentos da RAA-UFVJM, além de bússola, GPS e lupa. A partir da identificação e análise de toda a rede, solicita-se o mapa geológico conceitual, um perfil geológico da seção mais representativa do mapa e, uma interpretação da história geológica. Nesta atividade, pode-se incluir perguntas-chave que os estudantes devem buscar responder a partir dos afloramentos artificiais, como por exemplo: (i) existem evidências da direção de transporte sedimentar em alguma das camadas encontradas? Se sim, qual é esta direção? Qual foi a evidência encontrada? (ii) existe alguma feição geológica relacionada ao resfriamento magmático? Se sim, qual é? (iii) quantos eventos deformacionais estão registrados na área? Descreva cada um deles.

A RAA-UFVJM, aqui utilizada como estudo de caso, tem se mostrado um valioso recurso pedagógico para o curso de Engenharia Geológica da UFVJM, proporcionando aos alunos uma oportunidade de exercitar conteúdos teóricos diversos e de aprender e exercitar o uso de equipamentos de coleta de dados geológicos. Dentre as unidades curriculares, as mais favorecidas com a criação da rede são: i) Sistema Terra: uma vez que essa disciplina oferece um alicerce teórico para as demais disciplinas do curso, podem ser realizadas atividades introdutórias envolvendo identificação e descrição de rochas e estruturas, uso de bússola e as notações de medidas, além do raciocínio geológico, conferindo aos discentes maior preparo para as futuras disciplinas; ii) Desenho Aplicado à Geologia: nesse contexto podem ser realizadas atividades envolvendo fundamentos de cartografia e confecção de mapas e perfis geológicos; iii) Geologia Estrutural: por se tratar de uma disciplina de nível mais avançado no curso, podem ser realizadas práticas introdutórias de identificação de estruturas, bem como coleta, tratamento e interpretação de medidas estruturais; iv) Disciplinas de Petrologia e Petrografia: no âmbito dessas disciplinas podem ser realizadas atividades específicas, envolvendo a descrição mineralógica detalhada das rochas em escalas macroscópica e microscópica, identificação e interpretação de texturas e estruturas sedimentares, ígneas e metamórficas; v) Mapeamento Geológico: se utilizada em sua totalidade, a rede oferece a possibilidade de simular uma experiência completa de mapeamento geológico.

\section{Discussão}

$\mathrm{Na}$ literatura geológica existem poucas menções a experiências didáticas utilizando afloramentos artificiais. Dillon (2000) apresenta a instalação de um "jardim de rochas" na University of Western Ontario (Canadá), onde diversas amostras rochosas foram dispostas de modo a oferecer uma experiência didática de mapeamento geológico em uma pequena área (c. $500 \mathrm{~m}^{2}$ ), simulando a estratigrafia real da região. Totten (2003) descreve a construção de um afloramento artificial com finalidades didáticas na University of New Orleans (USA), motivada pela ausência de afloramentos rochosos naturais acessíveis aos estudantes daquela instituição. Já Benison (2005) reporta a instalação de onze afloramentos artificiais no campus da Central Michigan University (USA), cuja disposição espacial permite aos estudantes levantar e discutir uma coluna estratigráfica específica. Outros trabalhos apresentam experiências didáticas com afloramentos simulados, utilizando-se placas de compensado (Kastens \& Ishikawa, 2004) ou livros empilhados (Greenberg, 2002) dispostos de modo a simular estruturas geológicas. As RAA, conforme descritas neste trabalho, somam-se a estas propostas didáticas, apresentando as seguintes particularidades: (i) utilizam um grande número de amostras distintas, dispostas em uma grande área; (ii) os afloramentos artificiais são confeccionados com amostras reais de rocha, com feições geológicas (texturas, estruturas) reconhecíveis e coerentes com a proposta didática; (iii) a proposta aproveita irregularidades topográficas da área, permitindo a elaboração de uma experiência de mapeamento mais completa e complexa; (iv) possibilitar um uso versátil, com exercícios de diferentes graus de complexidade.

Atividades de campo são absolutamente essenciais no processo de formação de geólogos(as), fato amplamente discutido em diversos trabalhos acadêmicos (e.g. Compiani \& Carneiro 1993, Fantinel, 2000, 2005, Scortegagna \& Negrão, 2005, Carneiro \& Gonçalves, 2011, Andrade \& Carneiro 2019) e formalizado nas Diretrizes Curriculares Nacionais para os cursos de Geologia e Engenharia Geológica, que indicam uma carga horária mínima obrigatória de campo equivalente a 720h (Brasil, 2015, Carneiro, 2015). Segundo Fantinel (2005), 
durante o trabalho de campo, no contato com o objeto geológico, "intuição, criatividade e abdução formatam a imagem sintética inicial do objeto, as abstrações, as indagações e as primeiras hipóteses acerca dele. A racionalidade discrimina as características do objeto e lhes confere um ordenamento, uma representação simbólica e uma classificação". Do ponto de vista do ensino, Carneiro \& Gonçalves (2011) sugerem pontos importantes que devem ser trabalhados com os estudantes durantes as práticas de campo. São eles: i) narrativa temporal e construção do passado a partir dos traços encontrados no presente; ii) capacidade de comparar, identificar e classificar materiais terrestres (rochas e minerais); iii) desenvolvimento de habilidades cognitivas visuais e espaciais para construir a terceira dimensão do corpo geológico a partir da observação bidimensional; iv) capacidade de trabalhar com várias escalas (amostra manual, afloramento e perfil geológico) para fazer observações decisivas da reconstrução da história geológica. Apesar de não serem atividades de campo stricto sensu, as atividades utilizando RAA apresentam um grande potencial didático, no qual condensam-se todos os pontos expostos acima.

As RAA não substituem, em hipótese alguma, as práticas de campo em si e o contato com os objetos geológicos naturais e concretos, com suas complexidades e particularidades. No entanto, por constituírem ambientes controlados, em que a prática de campo é emulada com resultados previsíveis, as RAA possuem grande potencial didático e podem facilitar a introdução de conceitos, raciocínios e técnicas essenciais, otimizando, posteriormente, as atividades de campo. Neste sentido, a utilização de RAA como treinamento e introdução às práticas de campo dialoga com as observações de Rudwick (1996), que valoriza o movimento circular entre o "conhecido" e o "não conhecido" na construção do conhecimento geológico a partir das práticas de campo.

Compiani \& Carneiro (1993) propõem uma classificação pedagógica das atividades de campo, baseada nos seguintes parâmetros: objetivos pretendidos, visão de ensino predominante, relação com os modelos científicos existentes, método de ensino (com base na relação docente-aluno) e lógica predominante no processo de aprendizagem. Apesar de as atividades de ensino utilizando as RAA não serem atividades de campo sensu strictu, pode-se utilizar as categorias proposta por estes autores para classificá-las, partindo-se do princípio de que estas emulam diversos aspectos pedagógicos das ativida- des de campo. Para a classificação descrita abaixo (e sintetizada na Figura 3), tomou-se como referência a utilização completa da RAA, em uma atividade de mapeamento geológico simulado. Atividades simplificadas, que utilizem parcialmente a rede podem ter enfoques pedagógicos ligeiramente distintos.

Do ponto de vista dos objetivos da atividade, merecem destaque o "reconhecimento de feições e fenômenos da natureza" e o "desenvolvimento e exercício de habilidades específicas”, ainda que formulação de hipóteses e modelos e o aproveitamento de conhecimentos prévios também sejam objetivos importantes. Em relação à visão de ensino considera-se que as atividades com RAA tenham caráter formativo, uma vez que protagonizam a ação do aluno no processo de ensino-aprendizagem, e prezam pela construção do conhecimento geológico através da interação sujeito/objeto.

Ao analisar afloramentos artificiais distantes no espaço e serem estimulados a integrar estas informações utilizando seus conhecimentos teóricos, os estudantes têm uma introdução - em ambiente controlado - à construção de modelos geológicos completos a partir de registros fragmentados, traço marcante da práxis geológica. Além disso, ao se incluir discordâncias importantes no modelo geológico simulado (conforme o exemplo da RAA-UFVJM), estimulam-se os discentes a dar significado tanto ao registro geológico em si (tendo em vista suas formas de preservação) quanto à ausência deste (discordâncias, hiatos), o que configura um grande desafio metodológico da Geologia e das demais ciências históricas (Fantinel, 2005).

Do ponto de vista do uso, as RAA apresentam algumas vantagens importantes: (i) permitem práticas pedagógicas controladas, uma vez que pode-se projetar redes para representar situações geológicas específicas; (ii) os afloramentos artificiais não são fixos, o que permite remodelar a rede a qualquer momento para modificar a proposta pedagógica; (iii) baixo custo de instalação, principalmente se forem utilizadas amostras de fácil obtenção na região; (iv) fácil acesso, especialmente se montada nas imediações de instituições de ensino, podendo-se realizar práticas no tempo de uma aula regular. Vislumbra-se ainda a vantagem de instalação de RAA em locais com difícil acesso a afloramentos, o que ofereceria oportunidades mais frequentes de treinamento e exercício das práticas de campo aos discentes.

A presença de uma RAA no ambiente acadêmico possibilita, ainda, que os discentes organizem 
e realizem atividades autônomas, em que possam exercitar as habilidades de campo, o uso de equipamentos e o raciocínio geológico. A realização de atividades autônomas utilizando as RAA dialoga com as propostas de Scortegagna \& Negrão (2005), que discutem o papel didático das saídas autônomas de campo e indicam que este tipo de atividade permite ao aluno protagonizar a elaboração e teste de hipóteses, conferindo-lhes maior independência no campo.

Compiani \& Carneiro (1993) identificam nas atividades didáticas de campo diferentes graus de manutenção e/ou questionamento dos modelos científicos relacionados aos objetos geológicos envolvidos na atividade. A esse respeito, as atividades utilizando RAA representam uma situação à parte, uma vez que o modelo geológico de fundo é artificial e projetado especificamente para a atividade. Dada esta intencionalidade do modelo, considera-se que ele será tacitamente aceito e preservado no desenvolvimento das atividades didáticas. Pode-se imaginar, entretanto, a construção de RAA intencionalmente ambíguas, desenhadas para fomentar o questionamento fundamentado de um modelo geológico determinado.

Outro ponto singular do uso das RAA diz respeito ao método de ensino e à relação ensino-aprendizagem. As atividades de campo costumam ser classificadas em dirigidas e não-dirigidas, a depender do protagonismo assumido pelo professor ou aluno, respectivamente. As atividades em que a relação estabelecida é de equilíbrio, por sua vez, são classificadas como semi-dirigidas (e.g. Brusi, 1992, Compiani \& Carneiro, 1993, Scortegagna \& Negrão, 2005). No caso das atividades utilizando RAA, poder-se-ia pensar em um ensino do tipo dirigido, uma vez que o processo se desenvolve segundo ideias previamente estabelecidas pelo professor. Entretanto, como o modelo geológico simulado pela RAA não é revelado a priori aos discentes, estes assumem total protagonismo na descoberta do modelo geológico artificial, a partir da geração e interpretação autônoma de dados. Desta forma, considera-se que a relação de ensino-aprendizagem ocorra em equilíbrio, e classifica-se a atividade como semi-dirigida.

Por fim, pode-se discutir a lógica predominante nas atividades didáticas utilizando RAA. Compiani e Carneiro (1993) dividem as atividades de campo entre as que seguem uma "lógica da ciência" e as que seguem uma "lógica do aprendiz". No primeiro caso, a atividade é guiada por referenciais de conteúdo e esquemas de raciocínio próprios do método científico, e enfatiza-se a ilustração de aspectos teóricos, a transmissão de conceitos e o uso de técnicas específicas. No segundo, por sua vez, a atividade é pautada em formas de raciocínio espontâneas do estudante frente às situações geológicas apresentadas, e não são reprimidas eventuais imperfeições que seriam percebidas pela lógica científica. As RAA, nos moldes aqui descritos, são montadas com base em modelos pré-concebidos sob a ótica científica, que obedecem aos parâmetros da lógica geológica e a um ordenamento espaço-temporal coerente do registro geológico. Assim, pode-se dizer que a "lógica da ciência" é a lógica dominante nas atividades didáticas desenvolvidas com as RAA. Subordinadamente, no entanto, a informação geológica contida na RAA pode dar margem a interpretações alternativas e a visões inovadoras sobre o registro geológico presente, situações em que se poderia identificar influência da "lógica do aprendiz".

\begin{tabular}{|c|c|c|c|c|}
\hline Objetivos da atividade & Visão de ensino & $\begin{array}{c}\text { Modelos científicos } \\
\text { existentes }\end{array}$ & $\begin{array}{c}\text { Relação } \\
\text { ensino / aprendizagem }\end{array}$ & Lógica predominante \\
\hline \multirow{y}{*}{ Formativo } & $\begin{array}{c}\text { Aceitos e preservados } \\
\text { (modelo geológico } \\
\text { artificial) }\end{array}$ & $\begin{array}{c}\text { Equilíbrio } \\
\text { Ensino semi-dirigido }\end{array}$ & $\begin{array}{c}\text { Da ciência e, } \\
\text { subordinadamente, } \\
\text { do aprendiz }\end{array}$ \\
\hline
\end{tabular}

\begin{tabular}{|c|c|c|}
\hline \multicolumn{3}{|c|}{ Objetivos da atividade } \\
\hline $\begin{array}{c}\text { Aproveitar os } \\
\text { conhecimentos } \\
\text { geológicos prévios }\end{array}$ & $\begin{array}{c}\text { Reconhecer } \\
\text { feições e fenômenos } \\
\text { da natureza }\end{array}$ & $\begin{array}{c}\text { Elaborar dúvidas } \\
\text { e questões }\end{array}$ \\
\hline $\begin{array}{c}\text { Desenvolver e } \\
\text { exercitar habilidades }\end{array}$ & $\begin{array}{c}\text { Estruturar } \\
\text { hipóteses/sinteses } \\
\text { e criar conhecimento }\end{array}$ & $\begin{array}{c}\text { Desenvolver } \\
\text { atitudes e valores }\end{array}$ \\
\hline
\end{tabular}

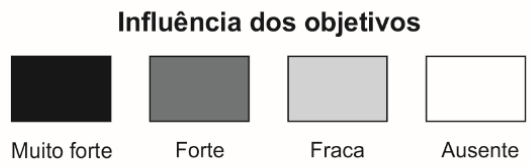

Figura 3. Classificação pedagógica principal das atividades didáticas utilizando RAA, adaptada da proposta de Compiani \& Carneiro (1993) para classificação de excursões de campo. A depender da atividade proposta, utilizar-se-iam outros parâmetros pedagógicos

\begin{tabular}{c|c|c|c|c|c}
\hline (C) Terrae Didat. & Campinas, SP & v.17 & $1-11$ & $\mathrm{e} 021013$ & 2021 \\
\hline
\end{tabular}




\section{Considerações finais}

As Redes de Afloramentos Artificiais são ferramentas pedagógicas versáteis, com potencial para impactar positivamente em disciplinas de várias áreas do conhecimento geológico, das mais básicas às mais avançadas. De pequenos perfis a extensos e complexos mapas geológicos, pode-se simular as mais diversas situações geológicas, aproveitando-se as potencialidades (topografia, vegetação, infraestrutura urbana) de cada área - em especial campi universitários, escolas e parques.

Apesar de não substituírem as atividades de campo, as Redes de Afloramentos Artificiais são excelentes ferramentas para a introdução e treinamento das habilidades e conceitos específicos do campo, e também dos modos de pensar que caracterizam a Geologia como ciência.

Espera-se que este trabalho inspire a criação de outras Redes de Afloramentos Artificiais, contribuindo para a disseminação e ensino das Geociências em seus vários níveis de abordagem.

\section{Agradecimentos}

Os autores agradecem ao Programa de Apoio ao Ensino de Gradação (PROAE) da UFVJM, pela concessão de bolsas aos discentes envolvidos no projeto, bem como aos professores Ticiano José Saraiva dos Santos e Celso Dal Ré Carneiro e a equipe editorial de Terre Didatica, cujos comentários e sugestões contribuíram para a melhoria substancial do manuscrito. M.K. é bolsista de produtividade do CNPq, e agradece o auxílio.

\section{Referências}

Andrade, W.S. \& Carneiro, C.D.R. (2019). Ilustrar ou induzir? Eis a questão... Os trabalhos de campo e seus papéis didáticos. Terre Didatica, 15, 1-8, e19050. doi: 10.20396/td.v15i0.8657610

Benison, K. C. (2005). Artificial Outcrops Give Real Experience in Interpreting a Geologic History: The CMUland Group Project for Historical Geology Courses. Journal of Geoscience Education, 53(5), 501-507. doi: 10.5408/1089-9995-53.5.501.

Brasil. Ministério da Educação. Conselho Nacional de Educação. Câmara de Educação Superior. (2015). Resolução 1, de 6 de janeiro de 2015. Institui as Diretrizes Curriculares Nacionais para os cursos de graduação na área da Geologia, abrangendo os cursos de bacharelado em Geologia e em Engenharia Geológica e dá outras providências. Brasília (DF), 6 jan. 2015. URL: http:// portal.mec.gov.br/index.php?option $=$ com_do$\mathrm{cman} \&$ view $=$ download\&alias $=16871$-res-cne-ces-
-001-06012015\&Itemid=30192. Acesso 06.03.2021.

Brusi, D. (1992). Reflexiones en torno a la didactica de las salidas de campo en Geologia (I): aspectos metodológicos. In: Simposio sobre enseñanza de la Geología, 7, Santiago de Compostela. Anais... Instituto de Ciências de Educación, Universidad Santiago de Compostela. p.363-389.

Carneiro, C. D. R. (2015). O Fórum Nacional de Cursos de Geologia e as diretrizes curriculares nacionais: histórico e perspectivas. Campinas, SP, Terree Didatica, 10(3), 191-203. doi: 10.20396/td. v10i3.8637316.

Carneiro, C. D. R. \& Gonçalves P.W. (2011). Actividades de campo en la asignatura Ciencia del Sistema Tierra: la Geología como estructura básica. Rev. de la Enseñanza de las Ciencias de la Tierra, 19(1), 48-56. URL: http://www.raco.cat/index.php/ECT/ article/view/244378/331350. Acesso 06.03.2021.

Carneiro, C. D. R., Cunha, C.A.L.S. \& Campanha, G.A.C. (1993). A teoria e a prática em geologia e o eterno retorno. Revista Brasileira de Geociências, 23(4), 339-346. URL: http://www.ppegeo.igc.usp. br/index.php/rbg/article/view/11661/11122. Acesso 06.03.2021.

Compiani, M. \& Carneiro, C. D. R. (1993). Os papéis didáticos das excursões geológicas. Enseñanza de las Ciências de la Tierra, 1(2), 90-98. URL: https:// www.raco.cat/index.php/ECT/article/view/88098. Acesso 06.03.2021.

Dillon, D. L., Hicock, S. R., Secco, R. A. \& Tsujita, C. J. (2000). A Geologic Rock Garden as an Artificial Mapping Area for Teaching and Outreach. Journal of Geoscience Education, 48(1), 24-29. doi: 10.5408/1089-9995-48.1.24.

Fantinel, L. M. (2000). Práticas de campo em geologia introdutória: papel das atividades de campo no ensino de fundamentos de geologia do curso de geografia. Dissertação de Mestrado. Universidade Estadual de Campinas. 124p. URL: http://repositorio.unicamp.br/handle/ REPOSIP/287216. Acesso 06.03.2021.

Fantinel, L. M. (2005). O ensino de mapeamento geológico no Centro de Geologia Eschwege, Diamantina - MG: análise de três décadas de práticas de campo (19702000). Tese de Doutorado. Universidade Estadual de Campinas. 257p. URL: http://repositorio. unicamp.br/handle/REPOSIP/287213. Acesso 06.03.2021.

Frodeman, R. (2010). O raciocínio geológico: a geologia como uma ciência interpretativa e histórica. Terra Didatica, 6, 85-99. doi: 10.20396/td.v6i2.8637460.

Kastens, K. \& Ishikawa, T. (2004). Mentally visualizing large geologic structures from field observations. NAGT On the Cutting Edge Workshop: Teaching structural geology in the $21^{\text {st }}$ century, Northampton, MA, Smith College. URL: https://serc. carleton.edu/NAGTWorkshops/structure04/activities/3866.html. Acesso 06.03.2021 
Rudwick, M. (1996). Geological travel and theoretical innovation: the role of 'liminal' experience. Social Studies of Science, XXVI, 143-59. doi: 10.1177/030631296026001007.

Scortegagna, A. \& Negrão, O. B. M. (2005). Trabalhos de campo na disciplina de Geologia Introdutória: a saída autônoma e seu papel didático. Terra Didatica, 1(1), 36-43. doi: 10.20396/td.v1i1.8637443

Totten, I. M. (2003). Using an artificial rock outcrop to augment student learning at an urban university. Tese de Doutorado. University of New Orleans, 169p. URL: https://ui.adsabs.harvard. edu/abs/2003PhDT.......109T/abstract. Acesso 06.03.2021.

Universidade Federal dos Vales do Jequitinhonha e Mucuri (UFVJM). (2011). Plano Diretor do Campus JK. URL: http://mapeamento.ufvjm.edu.br/. Acesso 06.03.2021. 